\title{
Exhaled nitric oxide in cystic fibrosis: relationships with airway and lung vascular impairments
}

\author{
D. Hubert, F. Aubourg, B. Fauroux, L. Trinquart, I. Sermet, G. Lenoir, A. Clément, \\ A. T. Dinh-Xuan, B. Louis, B. Mahut and C. Delclaux
}

ABSTRACT: A reduction of exhaled nitric oxide (NO) fraction and endothelial-mediated dysfunction have been reported in cystic fibrosis (CF). The aims of the present study were to search for relationships between flow-independent NO exchange parameters (bronchial NO flux $\left(\mathrm{J}^{\prime}\right.$ aw,NO) and alveolar NO concentration $\left(\mathrm{C}_{\mathrm{A}, \mathrm{NO}}\right)$ ) and lung function tests characterising airflow limitation and pulmonary vascular bed (capillary blood volume and physiological dead space/tidal volume $(V D / V T)$ ratio on exercise).

In total, 34 patients (16 children, 18 adults) with CF, without resting pulmonary hypertension, underwent spirometry, exhaled NO measurement (multiple constant flow analytical method), gas transfer assessment (carbon monoxide and NO, allowing the calculation of capillary volume and membrane conductance) and a graded exercise test with oxygen uptake $\left(V^{\prime} \mathrm{O}_{2}\right)$, carbon dioxide production $\left(\mathrm{V}^{\prime} \mathrm{CO}_{2}\right)$ and arterial blood gas evaluations.

Both $J^{\prime}$ aw,NO and $C_{A, N O}$ correlated positively with airflow limitation. $C_{A, N O}$ correlated positively with capillary/alveolar volume. During exercise, criteria of mild pulmonary vascular disease were evidenced in some patients that participated in exercise limitation (negative correlation between physiological $\mathrm{VD} / \mathrm{VT}$ and peak $V^{\prime} \mathrm{O}_{2}$ ). $\mathrm{CA}_{\mathrm{A}, \mathrm{NO}}$ at rest correlated positively with these parameters of wasted ventilation during exercise (physiological $V D / V T$, minute ventilation $\left(V^{\prime} E\right) / V^{\prime} \mathrm{CO}_{2}$ at ventilatory threshold and $V^{\prime} \mathrm{E} / V^{\prime} \mathrm{CO}_{2}$ slope).

Flow-independent exhaled NO parameters are linked to airway and early vascular diseases in patients with $\mathrm{CF}$.

KEYWORDS: Capillary blood volume, cystic fibrosis, exercise test, exhaled nitric oxide

$\mathbf{N}$ ew measures are needed that detect subtle changes before overt decline in lung function in patients with cystic fibrosis (CF) [1]. There are several lines of evidence suggesting that nitric oxide $(\mathrm{NO})$ could constitute a key mediator of CF pathophysiology due to its broad spectrum bactericidal properties, its role in modulating epithelial ion transports, and its bronchovasomotor and anti-proliferative functions [2]. Interestingly, NO can be measured in exhaled gas, but its sources (cellular and enzymatic), roles and relationships with disease markers remain debated. Due to the broad spectrum of activities of this messenger one may hypothesise that its measure could reflect or could be linked to various aspects of CF lung disease.

Along this line, NO fraction has been found to be decreased in upper (nasal) airways in $\mathrm{CF}$ patients, whereas exhaled $\mathrm{NO}$ fraction $(\mathrm{FeNO})$ had a nil to moderate decrease from infancy to adulthood [3-7]. This variable decrease in exhaled NO has been related to a defective expression of type 2 inducible NO synthase, which may participate to the susceptibility to Pseudomonas aeruginosa infection (bactericidal function) [8]. Reduced exhaled NO has also been related to impaired nasal potential difference in patients with CF (epithelial ion transport) [9]. Finally, only one study has described a negative correlation between exhaled $\mathrm{NO}$ and airflow limitation in CF patients (loss of anti-proliferative function linked to remodelling) [4] while other studies did not find such a relationship [5-7].

Therefore, our aim was to assess whether exhaled NO measurement is associated with lung function parameters obtained at rest and during exercise reflecting both airway and vascular impairments due to CF disease. To this end, a detailed analysis of exhaled NO was performed,
AFFILIATIONS

For affiliations, please see Acknowledgements section.

CORRESPONDENCE

C. Delclaux

Département de Physiologie - RadioIsotopes,

Clinique de la Dyspnée

Hôpital européen Georges Pompidou 20-40 rue Leblanc

75908 Paris

Cedex 15

France

E-mail: christophe.delclaux@

egp.aphp.fr

Received:

Oct 302008

Accepted after revision:

Jan 132009

First published online:

Feb 122009 
which gives flow-independent parameters of NO exchange dynamics related to its physiology. Exhaled NO measurement at a single expiratory flow rate is a global assessment since exhaled NO output is the sum of alveolar and conducting airway NO outputs [10]. We hypothesised that the two origins of exhaled NO may be linked to different pulmonary function parameters, reflecting different aspects of CF pathophysiology. Consequently, the aim of the current prospective observational study was to describe exhaled NO using partitioning of its origins (from alveoli and conducting airways) to further assess the relationships between flow-independent $\mathrm{NO}$ exchange parameters (alveolar $\mathrm{NO}$ concentration $(\mathrm{CA}, \mathrm{NO})$ and maximum conducting airway NO flux $\left(J^{\prime}\right.$ aw,NO), based on a twocompartment model of NO exchange) and lung function parameters. It was hypothesised that exhaled NO exchange parameters of conducting airways may be linked to airflow limitation, whereas CA,NO may be linked to tests describing the alveolar-capillary transfer of gas at rest and during exercise. Alveolar NO fraction has been shown to be either decreased or increased in CF patients [6, 7]. The endothelial origin of $\mathrm{CA}, \mathrm{NO}$ remains a subject of controversy; nevertheless, a frequent impairment of endothelium-mediated vasodilation has been shown ex vivo on pulmonary arterial rings of CF patients with end-stage lung disease, which may occur before obvious pulmonary hypertension [11]. An NO-dependent impairment in flow-mediated dilation may impair the ability of the pulmonary vascular bed to dilate on exercise [12], resulting in an increased physiological dead space volume (VD)/tidal volume $(V \mathrm{~T})$ ratio. Therefore, one aim was to assess whether $\mathrm{CA}, \mathrm{NO}$ could be linked to criteria of wasted ventilation on exercise. To this end, only patients without severe airflow limitation and pulmonary hypertension were enrolled in a prospective observational study to evaluate whether exhaled NO parameters could constitute markers of bronchial and lung vascular impairments.

\section{METHODS}

\section{Patients}

Children or adults with $\mathrm{CF}$ were recruited from three $\mathrm{CF}$ centres (Cochin, Trousseau and Necker Hospitals, all Assistance Publique - Hôpitaux de Paris, Paris, France). Ethical approval for the study protocol was received from a research ethics committee (Comité de Protection des Personnes IDF IV, Paris) and informed consent was obtained.

Inclusion criteria were a diagnosis of CF confirmed by sweat tests (chloride concentrations exceeding $60 \mathrm{mmol} \cdot \mathrm{L}^{-1}$ ) and/or by two mutations of the $\mathrm{CF}$ transmembrane conductance regulator (CFTR) gene, a stable clinical condition, the absence of hepatic cirrhosis or asthma, an immunoglobulin $\mathrm{E}$ level $<200 \mathrm{UI} \cdot \mathrm{L}^{-1}$, no pulmonary arterial hypertension at rest on echocardiography and an age of $\geqslant 10$ yrs. All functional tests were obtained within a week.

\section{Exhaled NO}

All exhaled $\mathrm{NO}$ and gas transfer measurements were performed in Georges Pompidou European Hospital (Paris). As discordant results concerning alveolar NO measurements have previously been described using different analytical methods based on the same model of NO exchange dynamics $[6,7]$, we used the two analytical approaches in our patients that have previously been described and compared in detail [13].

The dependency of the FeNO on exhalation flow rate can be explained by a simple two-compartment model of the lung that has been used by several research groups. This two-compartment model describes exhaled NO arising from two compartments, the airways and the alveolar region, using three flow-independent exchange parameters: one describing the alveolar region (the steady-state $\mathrm{CA}, \mathrm{NO}$ ), and two describing the airway region (airway NO diffusing capacity and either the maximum J'aw,NO or the airway wall NO concentration).

Two analytical approaches have been described in the literature to estimate flow-independent NO parameters: multiple constant flow (MCF) and dynamically changing flow methods. Their methodologies are briefly described.

\section{MCF method}

MCF J'aw,NO and CA,NO were calculated by a chemiluminescent analyser (ENDONO 8000; Seres, Aix-en-Provence, France) after obtaining several exhaled NO measurements at different expiratory flow rates (four to six expiratory flows between 50 and $200 \mathrm{~mL} \cdot \mathrm{s}^{-1}$ ), using the previously described linear approach [10]. The criteria used for each exhaled NO measurement were those recommended in international guidelines [14]. We used a validity criterion of this linear approach $\left(r^{2} \geqslant 0.64\right)$, as previously described [13]. Since FeNO was measured at $50 \mathrm{~mL} \cdot \mathrm{s}^{-1}$ during the multiple exhalation method, results of FeNO measured at $0.05 \mathrm{~L} \cdot \mathrm{s}^{-1}\left(F_{\mathrm{eNO}}, 0.05\right)$ were provided.

\section{Dynamically changing flow method}

The method consisted of an inspiration to total lung capacity, a 10 -s breath hold followed by a slow (5-8 s) exhalation to functional residual capacity against a $7.5 \mathrm{~cm} \mathrm{H}_{2} \mathrm{O}$ positive expiratory pressure valve. The analog signals of $\mathrm{NO}$ and flow were digitised; mathematical estimation of the parameters (dynamically changing flow (DCF) CA,NO, airway NO diffusing capacity and DCF $J^{\prime}$ aw,NO) has previously been described in detail [13].

\section{CO and NO transfers}

Transfer factors of the lung for $\mathrm{NO}$ and $\mathrm{CO}(\mathrm{TL}, \mathrm{NO}$ and TL,CO, respectively) were obtained from two separate measurements. The single, rapid, maximal exhalation at constant flow rate method described by PERILLO et al. [15] was used for measuring $T \mathrm{~L}, \mathrm{NO}$. For measurement of $\mathrm{TL}, \mathrm{CO}$, the single-breath determination of $\mathrm{CO}$ uptake in the lung was determined according to recent international guidelines with automated equipment (MasterScreen Body; Jaeger, Wurzburg, Germany) [16].

Membrane conductance and pulmonary capillary blood volume $\left(V_{\mathrm{c}}\right)$ available for gas exchange were calculated according to the equation of ROUGHTON and FORSTER [17] and values of the different constant factors were selected according to GLENET et al. [18].

\section{Spirometry}

Spirometry was obtained in each centre. Measurement and theoretical values followed recent international guidelines [19] 


\section{Exercise test}

Two investigators (F. Aubourg and C. Delclaux) performed the symptom limited incremental exercise tests. All tests consisted of $5 \mathrm{~min}$ of rest, $3 \mathrm{~min}$ of warm-up $(20 \mathrm{~W})$, the incremental work-rate period, and 3-min resting recovery. A ramp protocol was used with an incremental rate of $5-15 \mathrm{~W} \cdot \mathrm{min}^{-1}$ judged by the operator. Exercise tests were terminated at the point of symptom limitation. Arterial oxygen saturation measured by pulse oximetry, electrocardiographic monitoring of the heart rate and blood pressure by indirect sphygmomanometry were monitored. Breath by breath data were collected while subjects breathed through a mouth piece (with a nose clip). Computer software (SensorMedics, Yorba Linda, CA, USA) calculated minute ventilation $\left(V^{\prime} \mathrm{E}\right)$, oxygen uptake $\left(V^{\prime} \mathrm{O}_{2}\right)$, carbon dioxide production $\left(V^{\prime} \mathrm{CO}_{2}\right)$, end-tidal $\mathrm{CO}_{2}$ tension, $V \mathrm{~T}$ and breathing frequency. Slopes of $V^{\prime} \mathrm{O}_{2} /$ power $\mathrm{W}$, heart rate $/ V^{\prime} \mathrm{O}_{2}, V^{\prime} \mathrm{E} /$ $V^{\prime} \mathrm{O}_{2}, V^{\prime} \mathrm{E} / V^{\prime} \mathrm{CO}_{2}$ and anaerobic threshold (ventilatory threshold, using the V-slope method) were calculated. At rest and immediately before the end of exercise arterial sampling was performed (blood gas and lactate analyses) allowing the calculation of arterial minus end-tidal $\mathrm{CO}_{2}$ tension $\left(P(\mathrm{a}-\mathrm{ET}) \mathrm{CO}_{2}\right)$ and physiological $V \mathrm{D} / V \mathrm{~T}$ ratio (a value of $V \mathrm{D} / V \mathrm{~T}$ ratio $>0.25$ may be considered as abnormal in these young subjects [20]). Subjects were asked to score their sense of breathlessness and muscle effort/fatigue using Borg scales during the test. Predicted values of $V^{\prime} \mathrm{O}_{2}$ were calculated according to reference equations obtained in children and adults [21]. Ventilation was expressed as a percentage of predicted maximal voluntary ventilation (MVV):

\section{$\left(\left(\mathrm{MVV}-V^{\prime} \mathrm{E}\right) / \mathrm{MVV}\right)$}

The predicted MVV was calculated as $40 \times$ forced expiratory volume in $1 \mathrm{~s}$ (FEV1) [21].

\section{Statistical analysis}

We included 34 patients because using this sample size Ho et al. [4] demonstrated a significant relationship between exhaled $\mathrm{NO}$ and airflow limitation. All results are expressed as median (25th-75th percentile). Since the shape of the relationship between parameters cannot be inferred, only Spearman correlation coefficients were determined (rho $(\rho)$ values are given). Qualitative variables were compared using the MannWhitney U-test or Kruskall-Wallis test as appropriate. Statistical significance was defined by $p \leqslant 0.05$.

\section{RESULTS}

In total, 34 patients were prospectively included; their clinical characteristics are described in table 1 while their functional characteristics are described in table 2 (resting function) and table 3 (exercise function). In relation to table 2, SURI et al. [7] observed the following exhaled NO median (range) values in 22 children with cystic fibrosis (CF) using the MCF method: CA,NO $2.2(0.6-5.6) \mathrm{ppb}$ and $J^{\prime}$ aw,NO $27(4-75) \mathrm{nL} \cdot \mathrm{min}^{-1}$. SHIN et al. [6] observed the following exhaled $\mathrm{NO}$ values in nine children with CF using the DCF method: $\mathrm{CA}, \mathrm{NO} 2.0 \pm 1.2 \mathrm{ppb}$, $J^{\prime}$ aw,NO $36 \pm 39$ nL.min ${ }^{-1}, D^{\prime}$ aw,NO $1.06 \pm 0.73$ nL.min ${ }^{-1} \cdot p^{p} b^{-1}$ and $C^{\prime}$ aw,NO $38 \pm 25 \mathrm{ppb}$

\section{Exhaled NO}

The MCF method demonstrated that expiratory flow rate and exhaled NO output were linearly related in all patients (see $r^{2}$ value, table 2) suggesting that the two-compartment model adequately describes exhaled NO output in CF patients. The results of both analytical methods were linearly correlated $\left(r^{2}=0.63\right.$ and $r^{2}=0.47$ for $\mathrm{CA}, \mathrm{NO}$ and $J^{\prime}$ aw,NO, respectively; $p<0.0001$ for both comparisons). It has to be noted that the MCF method gave higher values of $\mathrm{CA}, \mathrm{NO}$ and lower values of $J^{\prime}$ aw,NO as compared with the DCF method $(\mathrm{p}<0.01$ for both comparisons). Since the two analytical methods gave quite similar results (table 2), correlations obtained with the MCF method are further reported for simplicity (since this method is widely used), and only additional results obtained with the DCF method are given.

Exhaled $\mathrm{NO}$ values (CA,NO and $J^{\prime}$ aw,NO) were not significantly modified by pancreatic insufficiency (FeNO,0.05 7.6 (5.215.9) $\mathrm{ppb}$ versus without insufficiency 17.7 (10.7-23.5) ppb; $\mathrm{p}=0.20)$, diabetes, inhaled corticosteroid (FeNO,0.05 12.1 (6.0 18.2) ppb versus without steroid $7.7(5.9-13.6) \mathrm{ppb} ; \mathrm{p}=0.52)$ or inhaled $\beta_{2}$-agonist treatment (FeNO,0.05 7.1 (5.0-16.9) ppb versus without $9.1(6.8-15.3) \mathrm{ppb} ; \mathrm{p}=0.69)$, bacterial colonisation or by the mutation group.

\section{Lung capillary blood volume and membrane conductance}

On average, $T \mathrm{~L}, \mathrm{CO}$ was preserved in our CF patients (table 2). As $\mathrm{NO}$ can react with bacteria, we assessed whether lung bacterial colonisation modifies $\mathrm{TL}, \mathrm{NO}$, demonstrating similar values in patients with or without airway bacterial colonisation (data not shown).

\section{Exercise test}

Overall, a mild impairment in exercise capacity was evidenced (table 3). Peak $V^{\prime} \mathrm{O}_{2} \%$ predicted was related to $\mathrm{FEV} 1 \%$ pred $(\rho=0.37, p=0.034)$. Physiological dead space on peak exercise was not related to pulmonary function tests (FEV1 or $T \mathrm{~L}, \mathrm{CO}$, data not shown). The $V \mathrm{D} / V \mathrm{~T}$ ratio seemed to participate in exercise performance impairment as anaerobic threshold and peak $V^{\prime} \mathrm{O}_{2}$ (trend for oxygen pulse $\rho=-0.37, \mathrm{p}=0.066$ ) were negatively correlated with physiological $V \mathrm{D} / V$ T ratio (fig. 1). Ventilation/perfusion ratio $\left(V^{\prime} / Q^{\prime}\right)$ inequalities were evidenced in some patients and there was a negative relationship between arterial oxygen tension $\left(\mathrm{Pa}_{\mathrm{a}} \mathrm{O}_{2}\right)$ and $\mathrm{P}(\mathrm{a}-\mathrm{ET}) \mathrm{CO}_{2}$ at peak exercise $(\rho=-0.45, p=0.024)$.

Overall, 10 out of 26 patients had an increased physiological $V \mathrm{D} / V \mathrm{~T}$ ratio at peak exercise $>0.25$ (four out of $26>0.30$ ).

\section{Relationships between flow-independent exhaled NO exchange parameters and functional tests obtained at rest and during exercise}

Parameters characterising conducting airways

MCF J'aw,NO and FeNO,0.05 correlated positively with airflow limitation (FEV1 and FEV1/forced vital capacity (FVC); fig. 2). These relationships were still significant $(\rho=0.62, p=0.013$ for both comparisons) in patients without inhaled corticosteroid $(n=18)$, while the statistical significance was lost in patients $(n=16)$ receiving inhaled corticosteroid.

A relationship was evidenced between $J^{\prime}$ aw,NO and baseline $\mathrm{Pa}_{1} \mathrm{O}_{2} \quad(\rho=0.55, \mathrm{p}=0.005)$. The DCF method additionally demonstrated that the airway wall NO concentration (but not airway NO diffusing capacity) also correlated with airflow limitation $(\rho=0.51, p=0.011)$. 


\begin{tabular}{|c|c|}
\hline Clinical chare & \\
\hline Subjects & 34 \\
\hline Age yrs & $19(15-25)$ \\
\hline Children/adults & $16 / 18$ \\
\hline Female/male & $11 / 23$ \\
\hline Weight kg & $54(46-63)$ \\
\hline Height cm & $163(157-171)$ \\
\hline$B M I \mathbf{k g} \cdot \mathrm{m}^{-2}$ & $20.3(17.9-21.7)$ \\
\hline \multicolumn{2}{|l|}{ Mutations } \\
\hline F508del/F508del & 12 \\
\hline F508del/other & 17 \\
\hline No F508del mutation & 5 \\
\hline Pancreatic insufficiency & 29 \\
\hline Diabetes & 2 \\
\hline Bacterial airway colonisation & 29 \\
\hline Staphylococcus aureus & 26 \\
\hline Pseudomonas aeruginosa & 15 \\
\hline Inhaled corticosteroid & 16 \\
\hline Inhaled long-acting $\beta$-agonist & 17 \\
\hline MRC score & $1(1-2)$ \\
\hline BDI score & $9(7-10)$ \\
\hline
\end{tabular}

Data are presented as $\mathrm{n}$ or median (25th-75th percentile). BMI: body mass index; MRC: Medical Research Council dyspnoea scale (1-5, with 5 being the most severe score); BDI: Baseline Dyspnoea Index (1-12, with 12 being the least severe score). The MRC and BDI scores were significantly negatively correlated (data not shown).

\section{$\mathrm{CA}, \mathrm{NO}$}

A statistically significant relationship was observed between CA,NO and FEV1/FVC at rest (fig. 2). This relationship was still significant $(\rho=0.55, p=0.027)$ in patients without inhaled corticosteroids $(n=18)$, while the statistical significance was lost in patients $(n=16)$ receiving inhaled corticosteroids. A positive relationship was observed between $\mathrm{CA}_{\mathrm{A}} \mathrm{NO}$ and $V_{\mathrm{c}} /$ alveolar volume (VA; $\rho=0.55, \mathrm{p}=0.027)$.

During exercise, significant relationships were evidenced between $\mathrm{CA}, \mathrm{NO}$ and parameters of wasted ventilation: physiological $V \mathrm{D} / V \mathrm{~T}$ ratio $\rho=0.44, \mathrm{p}=0.046 ; V^{\prime} \mathrm{E} / V^{\prime} \mathrm{CO}_{2}$ at anaerobic threshold $\rho=0.49, \mathrm{p}=0.009$; and $V^{\prime} \mathrm{E} / V^{\prime} \mathrm{CO}_{2}$ slope (fig. 3).

\section{DISCUSSION}

The first result of the present physiological study shows that flow-independent NO exchange parameters are related to airflow limitation in young patients with CF. The second finding suggests that defective lung vascular recruitment/ dilation is present in $\mathrm{CF}$, independently of the severity of airflow limitation, and that the resulting wasted ventilation may mildly impair exercise capacity. The third result shows that $\mathrm{CA}, \mathrm{NO}$ at rest is linked to this wasted ventilation during exercise.

\section{Partitioning of exhaled NO}

The two-compartment model of NO exchange dynamics can be considered as valid when a linear relationship between expiratory flow and NO output is evidenced (agreement with the theoretical model) [22], such linearity was evidenced in all $\mathrm{CF}$ patients. Our values of $\mathrm{FeNO}, 0.05$ are in agreement with
TABLE 2 Results of resting pulmonary function tests

\begin{tabular}{|c|c|}
\hline Characteristic & Result \\
\hline Spirometry & 34 \\
\hline FEV1 \% pred & $71(54-94)$ \\
\hline $\mathrm{FEV}_{1} / \mathrm{FVC} \%$ & $76(70-84)$ \\
\hline$T L, C O$ & 32 \\
\hline VA L & $3.89(3.17-4.37)$ \\
\hline$T L, \mathrm{CO} / \mathrm{VA} \mathrm{mmol} \cdot \mathrm{min}^{-1} \cdot \mathrm{kPa}^{-1} \cdot \mathrm{L}^{-1}$ & $1.76(1.63-1.99)$ \\
\hline$T \mathrm{~L}, \mathrm{CO} \mathrm{mmol} \cdot \mathrm{min}^{-1} \cdot \mathrm{kPa}^{-1}$ & $6.77(5.88-7.86)$ \\
\hline$T L, C O \%$ pred & $74(67-85)$ \\
\hline TL,NO & 18 \\
\hline$T L, N O \mathrm{mmol} \cdot \mathrm{min}^{-1} \cdot \mathrm{kPa}^{-1}$ & $24.55(19.90-27.40)$ \\
\hline$D \mathrm{M}, \mathrm{CO} \mathrm{mmol} \cdot \mathrm{min}^{-1} \cdot \mathrm{kPa}^{-1}$ & $12.45(10.10-13.90)$ \\
\hline$V_{c} \mathrm{~mL}$ & $75(69-104)$ \\
\hline$T L, N O / T L, C O$ ratio & $3.35(3.20-3.82)$ \\
\hline \multicolumn{2}{|l|}{ Exhaled NO\# } \\
\hline MCF method & 30 \\
\hline$r^{2 *}$ & $0.97(0.93-0.98)$ \\
\hline CA,NO ppb & $3.3(2.4-6.4)$ \\
\hline$J^{\prime}$ aw,NO $\mathrm{nL} \cdot \mathrm{min}^{-1}$ & $17(9-30)$ \\
\hline FeNO,0.05 ppb & $8.4(6.2-16.2)$ \\
\hline DCF method & 26 \\
\hline CA,NO ppb & $2.2(1.2-5.0)$ \\
\hline$J^{\prime}$ aw,NO nL·min ${ }^{-1}$ & $29(18-60)$ \\
\hline$D^{\prime}{ }^{a w}, \mathrm{NO} \mathrm{nL} \cdot \mathrm{min}^{-1} \cdot \mathrm{ppb}^{-1}$ & $0.24(0.21-0.31)$ \\
\hline C'aw,NO ppb & $100(61-218)$ \\
\hline
\end{tabular}

Data are presented as $\mathrm{n}$ or median (25th-75th percentile). FEV1: forced expiratory volume in $1 \mathrm{~s}$; \% pred: \% predicted; FVC: forced vital capacity; $T L, C O$ : transfer factor of the lung for carbon monoxide; $V A$ : alveolar volume; $T L, N O$ : transfer factor of the lung for nitric oxide (NO); DM,CO: membrane diffusion capacity of carbon monoxide; $V_{c}$ : pulmonary capillary blood volume; MCF: multiple constant flow; CA,NO: alveolar NO concentration; J'aw,NO: airway NO flux; FeNO,0.05: exhaled NO fraction measured at $0.05 \mathrm{~L} \cdot \mathrm{S}^{-1}$; DCF: dynamically changing flow; $D^{\prime}$ aw,NO: airway NO diffusing capacity; $C^{\prime}$ aw,NO: airway wall NO concentration. Normal values (nonatopic subjects) for CA,NO, J'aw,NO, D'aw,NO and $C^{\prime}$ aw,NO using the DCF method are $1.9 \pm 0.8 \mathrm{ppb}, 28 \pm 16 \mathrm{~nL} \cdot \mathrm{min}^{-1}$, $0.31 \pm 0.01 \mathrm{~nL} \cdot \mathrm{min}^{-1} \cdot \mathrm{ppb}^{-1}$ and $90 \pm 52 \mathrm{ppb}$, respectively [13]. *: four patients were unable to perform both measures of exhaled NO and four additional patients were unable to perform the DCF method; " coefficient (linear regression) describing the linearity of the relationship between expiratory flow rate and NO output (linearity is an underlying assumption of the twocompartment model that needs to be verified) [13]

previous reports, suggesting a nil or mild decrease as compared with healthy subjects [5-7]. Two analytical approaches of exhaled NO data were used, based on the same two-compartment model. The results obtained from the two methods were correlated but not equivalent as previously shown [13]. The higher values of CA,NO in the multiple flow approach may be related to the higher influence of axial diffusion of NO in this method [23]. Our results are at variance with those of SHIN et al. [6] (DCF method), obtained from nine children with CF and are in agreement with those of SURI et al. [7] (MCF method). The former group of investigators demonstrated that airway NO diffusing capacity was elevated and both airway wall NO concentration and $\mathrm{CA}, \mathrm{NO}$ were reduced 


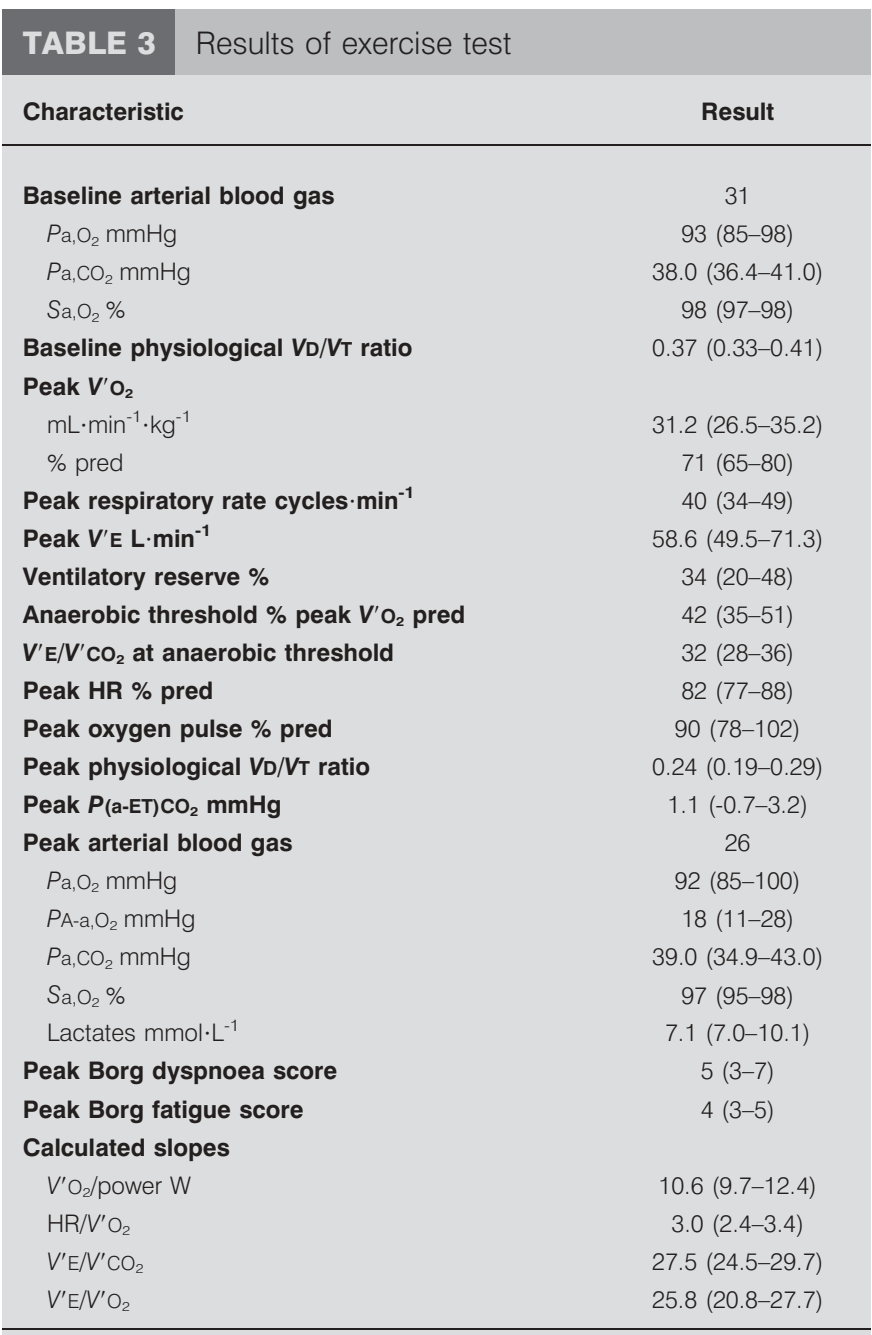

Data are expressed as $n$ or median (25th -75 th percentile). Three out of the 34 patients declined sampling of both baseline and peak arterial blood gas and we failed to sample arterial blood gas on peak exercise in five additional patients. $\mathrm{Pa}_{1} \mathrm{O}_{2}$ : arterial oxygen tension; $\mathrm{Pa}_{\mathrm{a}} \mathrm{CO}_{2}$ : arterial carbon dioxide tension; $\mathrm{Sa}_{\mathrm{O}_{2}}$ : arterial oxygen saturation; $V_{D}$ : dead space volume; $V_{T}$ : tidal volume; $V^{\prime} \mathrm{O}_{2}$ : oxygen uptake; \% pred: \% predicted; $V^{\prime} E$ : minute ventilation; $V^{\prime} \mathrm{CO}_{2}$ : carbon dioxide production; HR: heart rate; $P(\mathrm{a}-\mathrm{ET}) \mathrm{CO}_{2}$ : arterial minus end-tidal carbon dioxide tension; $\mathrm{PA}-\mathrm{a}, \mathrm{O}_{2}$ : alveolar-arterial oxygen tension difference.

compared with healthy subjects, giving normal FeNO values using the DCF method. Of note, all their subjects with CF had atopy, were receiving albuterol and seven out of nine patients had a reactive airway disease and were receiving inhaled steroids, which may have impacted their results [6]. The study by SURI et al. [7], used a multiple flow rate measurement of exhaled NO and showed an increase in alveolar $\mathrm{NO}$ in $\mathrm{CF}$ patients. The enzymatic and cellular sources of exhaled NO remain largely unknown in both healthy and CF subjects. Nevertheless, NO synthases 2 (NOS2) and airway epithelial cells seem to be the main contributors for the bronchial origin of exhaled NO, and a reduction of NOS2 expression in bronchial epithelium has been demonstrated in CF [8]. The sources of alveolar NO, the concentration of which is near nil in healthy subjects, are undetermined; but there are arguments
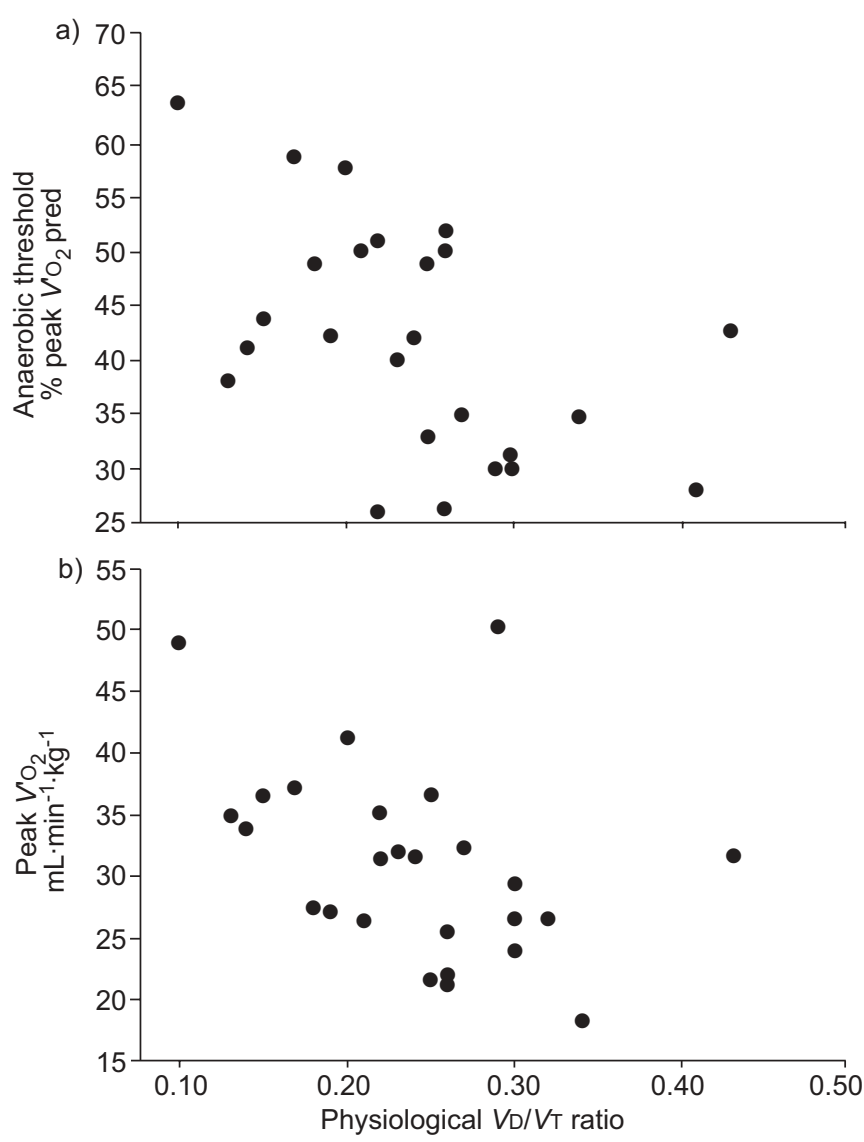

FIGURE 1. Wasted ventilation impairs exercise performance. The relationships between peak physiological dead space volume (VD)/tidal volume (VT) ratio and both a) anaerobic threshold $(\rho=-0.47, p=0.025)$ and $b)$ exercise performance $(\rho=-0.50, p=0.012)$ are described. $V^{\prime} \mathrm{O}_{2}$ : peak oxygen uptake; pred: predicted.

for an epithelial rather endothelial origin in the healthy condition. $\mathrm{CA}, \mathrm{NO}$ increases in inflammatory settings at least due to macrophage and/or endothelial/epithelial stimulation [10].

The reduction in exhaled NO is linked to airflow limitation Our study shows that $\mathrm{NO}$ exchange parameters characterising conducting airways are related to the degree of airflow limitation. In our study, FeNO,0.05 was also linked to bronchial obstruction, as previously suggested by a single study [4]. Other investigators did not find such a relationship, which may be related to bronchial participation to $F$ eNO, this depends on the value of the expiratory flow rate chosen. Furthermore, we eliminated some potential confounders (atopy, asthma and cirrhosis) that may have favoured this relationship. We also showed that the statistical significance of the relationship was lost in patients receiving inhaled corticosteroids. Our results suggest that $\mathrm{NO}$ deficiency in conducting airways may participate in bronchial obstruction since GRASEMANN et al. [24] have shown that nebulised L-arginine not only significantly increased exhaled NO concentration but also resulted in a sustained improvement of FEV1 in patients with CF. Interestingly, in this latter study, oxygen saturation also increased significantly after the inhalation of L-arginine, which suggests an effect of $\mathrm{NO}$ on $V^{\prime} / Q^{\prime}$ matching (we found a relationship between $\mathrm{Pa}_{2} \mathrm{O}_{2}$ and $J^{\prime}$ aw,NO) [24]. We did not find 

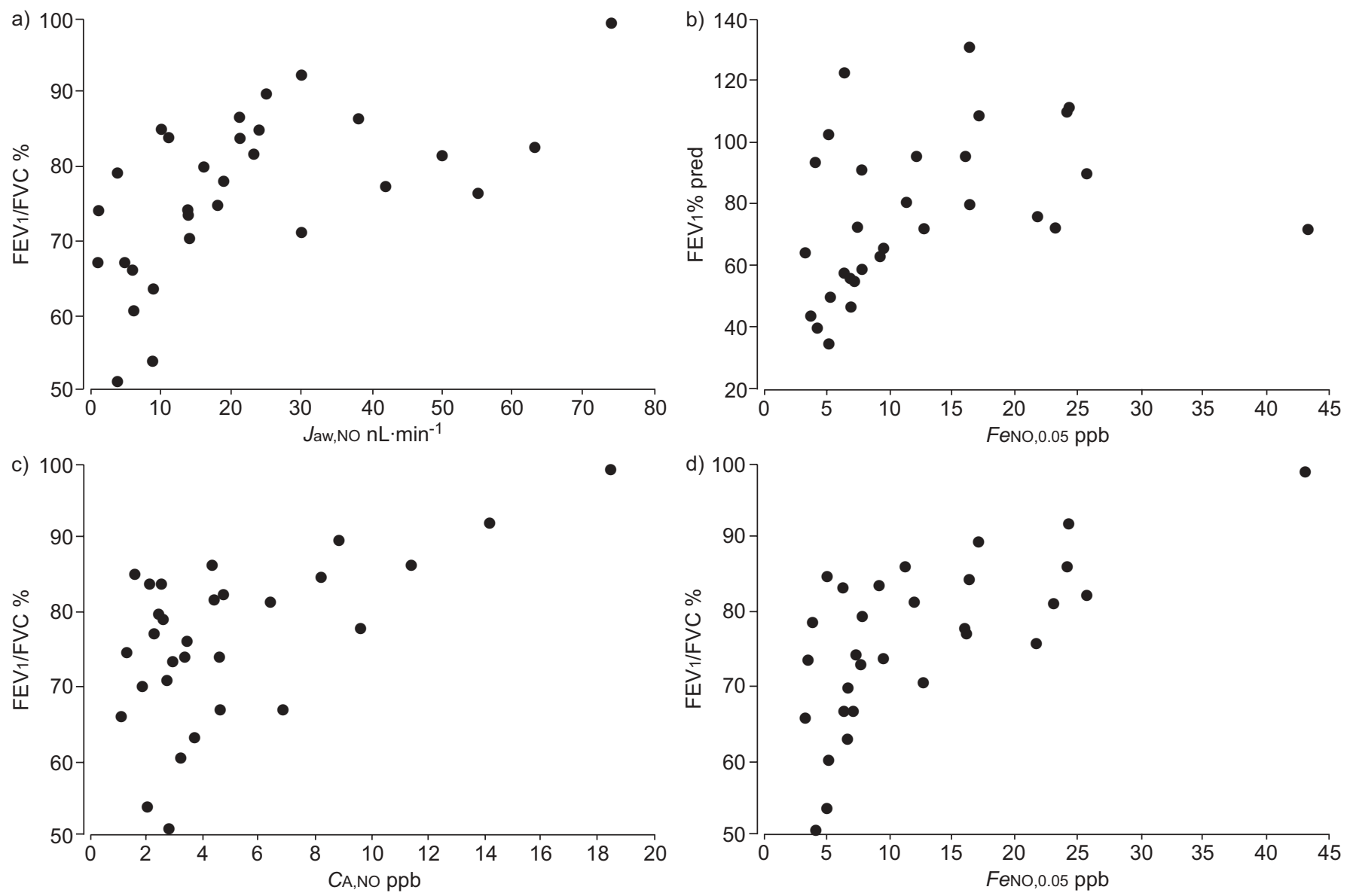

FIGURE 2. Reduction of exhaled nitric oxide (NO) is associated with airflow limitation. The relationships between airflow limitation (forced expiratory volume in $1 \mathrm{~s}$ (FEV1) and $\mathrm{FEV}_{1}$ /forced vital capacity (FVC) ) and a) bronchial maximum airway NO flux ( $\mathrm{J}^{\prime}$ aw,NO; $\left.\rho=0.64, p=0.0006\right)$, b and d) global exhaled NO fraction (FeNO,0.05; b) $\rho=0.51$ $p=0.006 ; d) \rho=0.63, p=0.0007$ ), and $c$ ) alveolar NO concentration ( $C A, N O ; \rho=0.43, p=0.21$ ) are described. Exhaled NO parameters were obtained using the multiple constant flow method. FEV $1 \%$ pred also correlated with $J$ 'aw,NO $(\rho=0.52, p=0.005)$. \% pred: \% predicted.

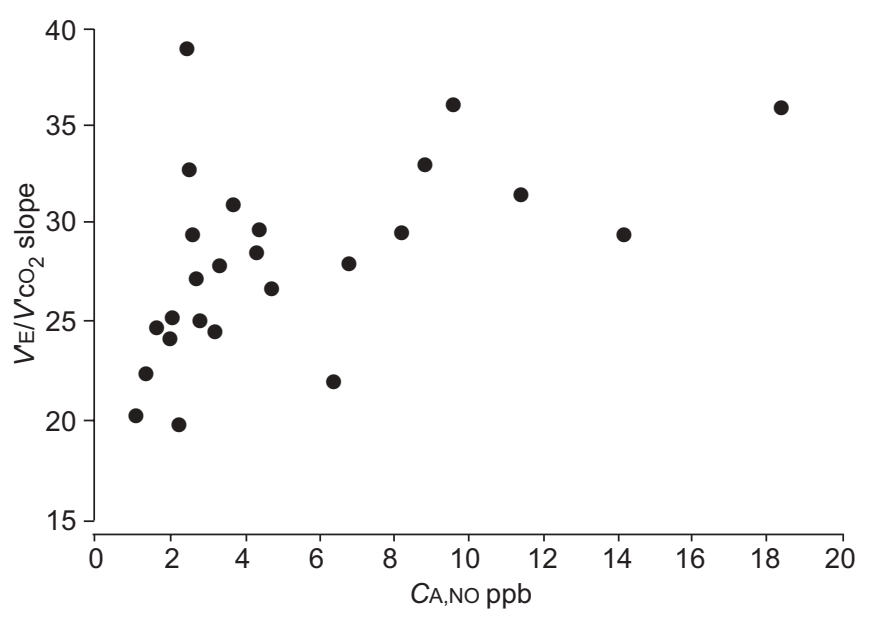

FIGURE 3. Increased alveolar nitric oxide concentration $(\mathrm{CA}, \mathrm{NO})$ at rest is associated with increased wasted ventilation during exercise. The relationship between $C A, N O$ and minute ventilation $\left(V^{\prime} E\right) /$ carbon dioxide production $\left(V^{\prime} \mathrm{CO}_{2}\right)$ slope is shown. $\rho=0.61, p=0.002$. that bacterial colonisation was associated with lower levels of FeNO,0.05 or flow-independent NO exchange parameters, which is at variance with the results obtained by KEEN et al. [5]. GIRGIS et al. [25] have observed a decrease in FeNO in patients with pulmonary arterial hypertension. Interestingly, they observed that bosentan reversed this defect, suggesting that suppression of NO may have been caused by endothelin. Along this line, we have recently shown that endothelial dysfunction in CF seems to be mediated by activation of the endothelin pathway [11].

\section{Transfer of gas in CF lung}

The diffusion capacity in children with CF is often preserved, despite ongoing airflow limitation [26]. Only one recent study to our best knowledge has reported values of $V_{\mathrm{c}}$ available for gas exchange and TL,NO/TL,CO ratio in CF patients [27]. Our results are in agreement with the DRESSEL et al. [27] study results, showing a preserved $V_{\mathrm{c}}$ and a slightly decreased ratio, which may suggest an increased thickness of the alveolar blood barrier [18]. At rest, CA,NO correlated positively with $V_{\mathrm{c}} /$ $V A$, which may argue for both NO-related vasodilation or vascular release of NO [12]. 


\section{Vascular impact of CF disease suggested by exercise test results}

CF subjects have a reduced peak exercise capacity that seems partly related to nonpulmonary factors in patients with mild to moderate disease [28]. In more severe patients (FEV1 <40\%), ventilatory limitation seems to become a main limiting factor to exercise [28]. To our knowledge, few data are available in CF patients of indirect assessment of lung vascular recruitment/ dilation (physiological $V \mathrm{D} / V \mathrm{~T}$ ratio, $\mathrm{P}(\mathrm{a}-\mathrm{ET}) \mathrm{CO}_{2}$, alveolar-arterial oxygen tension difference). Usually, CF is not considered as a disease with an important pulmonary vascular impact. Nevertheless, pulmonary hypertension can occur in CF with a dramatically negative effect on survival [29]. Before obvious vascular remodelling leading to increased vascular resistance and hypertension, endothelial dysfunction of pulmonary arteries may occur. Along this line, MAUREY et al. [11] recently demonstrated that this endothelial dysfunction is common in end stage CF disease, and can be present despite the absence of resting pulmonary hypertension. Moreover, the vasodilator property of CFTR in pulmonary arteries has also been shown [30]. We therefore hypothesised that endothelial dysfunction may be associated with defective vasodilation of pulmonary vessels during exercise. Our results suggest that defective dilation on exercise exists since a significant alveolar $V D$ can be measured at peak exercise in some CF patients (four to 10 out of 26). Furthermore, this defective vasodilation tends to impair oxygen pulse (suggesting a reduction of stroke volume on exercise), is associated with a decreased anaerobic threshold and impaired performance (peak $V^{\prime} \mathrm{O}_{2}$ ), and contributes to dyspnoea (increased ventilatory demand). Consequently, this vascular impairment seems to be of clinical significance. Our results are in agreement with other investigators who have demonstrated that, on exercise, pulmonary hypertension and reduction of stroke volume may occur in CF patients in the absence of obvious pulmonary hypertension [31]. On exercise, parameters reflecting alveolar dead space ventilation were related to $\mathrm{CA}, \mathrm{NO}$ at rest. One could hypothesise that an increase in CA,NO may occur because of a distal lung inflammatory process and/or thickening of the alveolar-capillary barrier. This increased concentration may increase capillary blood volume available for gas exchange (preserved $V_{c}$ in spite of reduced alveolar volume) at rest, but would be associated with defective vasodilation (increased physiological $V \mathrm{D} / V \mathrm{~T}$ ratio) on exercise due to the inability to further augment $\mathrm{NO}$ release (endothelial dysfunction). Further longitudinal studies are warranted to assess the prospective ability of $\mathrm{CA}, \mathrm{NO}$ to detect early vascular disease in $\mathrm{CF}$ patients.

\section{Limitations of the study}

Given the small number of patients studied here, our results must be considered as preliminary. All pulmonary function tests were not obtained in the whole group due to technical limitations in our youngest and most severely affected patients. We did not evidence dynamic hyperinflation during the exercise test in patients with mild to moderate airflow limitation, but inspiratory capacity on exercise was only measured in one centre (George Pompidou, data not shown). Consequently, abnormal dynamic ventilatory mechanics cannot be ruled out in all CF patients and may have participated, to some extent, to their functional limitation. Some patients were receiving inhaled treatment (corticosteroid and long-acting $\beta_{2}$-agonist) which may have modified exhaled NO. Nevertheless, the reduction of exhaled NO in patients treated with inhaled corticosteroid is modest in the setting of CF [32]. Our analytical methods did not take into account the trumpet-like morphology of conducting airways or axial diffusion from bronchial source to alveoli. This latter effect is probably of minimal importance in the setting of CF in which conducting $J^{\prime}$ aw,NO is not elevated. Whether our CA,NO truly reflects alveoli NO fraction is beyond the scope of this clinical study. The imperfection of the parameters describing NO exchange dynamics is balanced by their ability to describe useful clinical end-points.

In conclusion, our study shows that flow-independent $\mathrm{NO}$ exchange parameters are related to both bronchial and lung vascular impairments in $\mathrm{CF}$, namely the degree of airflow limitation (epithelial NO concentration of the conducting airway) and the capillary blood volume related to alveolar volume (CA,NO).

\section{SUPPORT STATEMENT}

The present study was part-financed by l'association Vaincre La Mucoviscidose (Paris, France) and was sponsored by the Direction de la Recherche Clinique et du Développement de Assistance Publique Hôpitaux de Paris (NO-CF study, P051101; Hôpital Saint-Louis, Paris, France).

\section{STATEMENT OF INTEREST}

A statement of interest for C. Delclaux can be found at www.erj. ersjournals.com $/ \mathrm{misc} /$ statements.dtl

\section{ACKNOWLEDGEMENTS}

D. Hubert: Assistance Publique - Hôpitaux de Paris, Hôpital Cochin Centre de Ressources et de Compétences pour la Mucoviscidose, Paris, France. F. Aubourg and A. T. Dinh-Xuan: Assistance Publique Hôpitaux de Paris, Hôpital Cochin, Service de Physiologie, Paris France. B. Fauroux and A. Clément: Assistance Publique - Hôpitaux de Paris, Hôpital Armand Trousseau, Centre de Ressources et de Compétences pour la Mucoviscidose, INSERM UMR-893 Equipe 12 and Université Pierre et Marie Curie, Paris, France. L. Trinquart: Assistance Publique - Hôpitaux de Paris, Université Paris Descartes, Hôpital européen Georges Pompidou, Unité de Recherche Clinique et d'Epidémiologie, Paris, France. L. Trinquart, G. Lenoir, A. T. DinhXuan and C. Delclaux: Université Paris Descartes, Paris, France. I. Sermet and G. Lenoir: Assistance Publique - Hôpitaux de Paris, Hôpital Necker - Enfants Malades, Centre de Ressources et de Compétences pour la Mucoviscidose, Paris, France. B. Louis: INSERM Unité U 841 Equipe 13, Faculté de Médecine de Créteil, Créteil, France. B. Mahut and C. Delclaux: Assistance Publique Hôpitaux de Paris, Hôpital européen Georges Pompidou, Service de Physiologie, Clinique de la Dyspnée, Paris, France.

The authors would like to thank: the patients who participated in the study; M. Riquelme, F. Le Bihan, M. Bokouabassa, and X. Gautier (Dept of Physiology, Pompidou Hospital, Assistance Publique - Hôpitaux de Paris, Paris, France) for expert technical assistance; G. Chatellier (director), B. Chevalier-Bidaud, I. Sauret, D. Mariolle, J-F. Leforestier and N. Lucas (Unité de Recherche Clinique et d'Epidémiologie, Pompidou Hospital, Assistance Publique - Hôpitaux de Paris) for data collection and management; and H. Mebarek and Y. Vacher (Direction de la Recherche Clinique et du Développement of Assistance Publique - Hôpitaux de Paris). 


\section{REFERENCES}

1 Corey M. Power considerations for studies of lung function in cystic fibrosis. Proc Am Thorac Soc 2007; 4: 334-337.

2 Ricciardolo FL, Sterk PJ, Gaston B, et al. Nitric oxide in health and disease of the respiratory system. Physiol Rev 2004; 84: 731-765.

3 Franklin PJ, Hall GL, Moeller A, et al. Exhaled nitric oxide is not reduced in infants with cystic fibrosis. Eur Respir J 2006; 27: 350-353.

4 Ho LP, Wood FT, Robson A, et al. The current single exhalation method of measuring exhales nitric oxide is affected by airway calibre. Eur Respir J 2000; 15: 1009-1013.

5 Keen C, Olin AC, Edentoft A, et al. Airway nitric oxide in patients with cystic fibrosis is associated with pancreatic function, Pseudomonas infection, and polyunsaturated fatty acids. Chest 2007; 131: 1857-1864

6 Shin HW, Rose-Gottron CM, Sufi RS, et al. Flow-independent nitric oxide exchange parameters in cystic fibrosis. Am J Respir Crit Care Med 2002; 165: 349-357.

7 Suri R, Paraskakis E, Bush A. Alveolar, but not bronchial nitric oxide production is elevated in cystic fibrosis. Pediatr Pulmonol 2007; 42: 1215-1221.

8 Kelley TJ, Drumm ML. Inducible nitric oxide synthase expression is reduced in cystic fibrosis murine and human airway epithelial cells. J Clin Invest 1998; 102: 1200-1207.

9 Texereau J, Fajac I, Hubert D, et al. Reduced exhaled NO is related to impaired nasal potential difference in patients with cystic fibrosis. Vascul Pharmacol 2005; 43: 385-389.

10 Delclaux C, Mahut B, Zerah-Lancner F, et al. Increased nitric oxide output from alveolar origin during liver cirrhosis versus bronchial source during asthma. Am J Respir Crit Care Med 2002; 165 : 332-337.

11 Maurey C, Henno P, Delclaux C, et al. Role of endothelin-1 in endothelial dysfunction in cystic fibrosis. Eur Respir J 2007; 30: Suppl. 51, 30s.

12 Ide $\mathrm{H}$, Nakano H, Ogasa $\mathrm{T}$, et al. Regulation of pulmonary circulation by alveolar oxygen tension via airway nitric oxide. J Appl Physiol 1999; 87: 1629-1636.

13 Mahut B, Louis B, Zerah-Lancner F, et al. Validity criteria and comparison of analytical methods of flow-independent exhaled NO parameters. Respir Physiol Neurobiol 2006; 153: 148-156.

14 American Thoracic Society, European Respiratory Society. ATS/ ERS recommendations for standardized procedures for the online and offline measurement of exhaled lower respiratory nitric oxide and nasal nitric oxide, 2005. Am J Respir Crit Care Med 2005; 171: 912-930.

15 Perillo IB, Hyde RW, Olszowka AJ, et al. Chemiluminescent measurements of nitric oxide pulmonary diffusing capacity and alveolar production in humans. J Appl Physiol 2001; 91: 1931-1940.

16 Macintyre N, Crapo RO, Viegi G, et al. Standardisation of the single-breath determination of carbon monoxide uptake in the lung. Eur Respir J 2005; 26: 720-735.
17 Roughton F, Forster R. Relative importance of diffusion and chemical reaction rates in determining rate of the exchange of gases in human lung, with special reference to true diffusing capacity of pulmonary membrane and volume of blood in the lung capillaries. J Appl Physiol 1957; 11: 290-302.

18 Glenet SN, De Bisschop C, Vargas F, et al. Deciphering the nitric oxide to carbon monoxide lung transfer ratio: physiological implications. J Physiol 2007; 582: 767-775.

19 Pellegrino R, Viegi G, Brusasco V, et al. Interpretative strategies for lung function tests. Eur Respir J 2005; 26: 948-968.

20 Wasserman K, Van Kessel AL, Burton GG. Interaction of physiological mechanisms during exercise. J Appl Physiol 1967; 22: 71-85.

21 Wasserman K, Hansen JE, Sue DY, et al. Normal values. In Wilkins LW, ed. Principles of exercise testing and interpretation. Including pathophysiology and clinical applications. 4th Edn. Philadelphia, Lippincott Williams \& Wilkins, 2005; pp. 160-182.

22 George SC, Hogman M, Permutt S, et al. Modeling pulmonary nitric oxide exchange. J Appl Physiol 2004; 96: 831-839.

23 Kerckx Y, Michils A, Van Muylem A. Airway contribution to alveolar nitric oxide in healthy subjects and stable asthma patients. J Appl Physiol 2008; 104: 918-924.

24 Grasemann H, Grasemann C, Kurtz F, et al. Oral L-arginine supplementation in cystic fibrosis patients: a placebo-controlled study. Eur Respir J 2005; 25: 62-68.

25 Girgis RE, Champion HC, Diette GB, et al. Decreased exhaled nitric oxide in pulmonary arterial hypertension: response to bosentan therapy. Am J Respir Crit Care Med 2005; 172: 352-357.

26 Merkus PJ, Govaere ES, Hop WH, et al. Preserved diffusion capacity in children with cystic fibrosis. Pediatr Pulmonol 2004; 37: 56-60.

27 Dressel H, Filser L, Fischer R, et al. Lung diffusing capacity for nitric oxide and carbon monoxide: dependence on breath-hold time. Chest 2008; 133: 1149-1154.

28 Moorcroft AJ, Dodd ME, Morris J, et al. Symptoms, lactate and exercise limitation at peak cycle ergometry in adults with cystic fibrosis. Eur Respir J 2005; 25: 1050-1056.

29 Fauroux B, Hart N, Belfar S, et al. Burkholderia cepacia is associated with pulmonary hypertension and increased mortality among cystic fibrosis patients. J Clin Microbiol 2004; 42: 5537-5541.

30 Robert R, Savineau JP, Norez C, et al. Expression and function of cystic fibrosis transmembrane conductance regulator in rat intrapulmonary arteries. Eur Respir J 2007; 30: 857-864.

31 Ionescu AA, Payne N, Obieta-Fresnedo I, et al. Subclinical right ventricular dysfunction in cystic fibrosis. A study using tissue Doppler echocardiography. Am J Respir Crit Care Med 2001; 163: 1212-1218.

32 Linnane SJ, Thin AG, Keatings VM, et al. Glucocorticoid treatment reduces exhaled nitric oxide in cystic fibrosis patients. Eur Respir J 2001; 17: 1267-1270. 